\title{
PENILAIAN KUALITAS HIDUP EORTC QLQ-C30 DAN EORTC QLQ-BN20 PADA PASIEN TUMOR PRIMER INTRAKRANIAL PASCATERAPI
}

\author{
QUALITY OF LIFE ASSESSMENT IN PRIMARY INTRACRANIAL TUMOR \\ AFTER TREATMENT USING EORTC QLQ-C30 AND EORTC QLQ-BN20 \\ Ratih Puspa, * Yusuf Wibisono, * Henny Anggraini Sadeli*
}

\begin{abstract}
Introduction: Increasing number of surviving primary intracranial tumor patients in line with discovery of new treatment will increase the patient's morbidity. This makes quality of life of patient need to be evaluated.

Aims: Assessed quality of life in primary intracranial tumor patients post treatment using European Organization for Research and Treatment of Cancer Quality of Life Questionnaire (EORTC QLQ-C30) along with EORTC QLQ-Brain Cancer Module (EORTC QLQ-BN20).

Methods: This was descriptive analytics-cross sectional study. Performed on primary intracranial tumor subjects during Desember 2017-January 2018 at neurology, neurosurgery, and radiotherapy outpatient Dr. Hasan Sadikin central general hospital Bandung. The obtained average value and the relationship between characteristics with quality of life were assessed using cross tabulation and analyzed with Statistical Package for Social Science (SPSS) version 24.0.

Results: There were 42 subjects. Highest scale group based on EORTC QLQ-C30 was cognitive function of func-

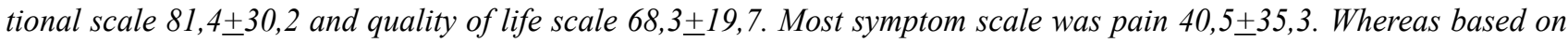
EORTC QLQ-BN20, most symptom was headache 49,2 $+37,7$. Tumor location was factor that affects quality of life.

Discussions: Subjects' quality of life were good based on EORTC QLQ-C30 and EORTC QLQ-BN20. Results were accordance with some previous studies, but assessment has done before and after treatment. Evaluation quality of life should be made before and after treatment. This study only assessed subject after treatment in Outpatient Installation. For future, it is necessary to conduct cohort study for quality of life evaluation.
\end{abstract}

Keywords: EORTC QLQ-BN20, EORTC QLQ-C30, primary intracranial tumor, quality of life

\section{ABSTRAK}

Pendahuluan: Meningkatnya jumlah pasien tumor primer intrakranial yang bertahan hidup sejalan dengan ditemukannya terapi baru akan meningkatkan morbiditas pasien. Hal ini membuat kualitas hidup pasien perlu dievaluasi.

Tujuan: Menilai kualitas hidup pada pasien tumor primer intrakranial pascatindakan dengan menggunakan European Organization for Research and Treatment of Cancer Quality of Life Questionnaire (EORTC QLQ-C30) bersamaan dengan EORTC QLQ-Brain Cancer Module (EORTC QLQ-BN20).

Metode: Penelitian deskriptif analitik yang dilakukan secara potong lintang, dilakukan pada subjek tumor primer intrakranial selama Desember 2017-Januari 2018 di instalasi rawat jalan neurologi, bedah saraf, dan radioterapi RSUP Dr. Hasan Sadikin, Bandung. Uji statistik untuk menilai rerata nilai yang didapat serta hubungan karakteristik dan kualitas hidup dengan tabulasi silang, kemudian diolah dengan Statistical Package for Social Science (SPSS) versi 24.0.

Hasil: Didapatkan 42 subjek. Kelompok skala paling tinggi berdasarkan EORTC QLQ-C30 adalah skala fungsional yaitu fungsi kognitif $81,4 \pm 30,2$ dan skala kualitas hidup $68,3 \pm 19,7$. Skala keluhan terbanyak nyeri $40,5 \pm 35,3$. Sedangkan berdasarkan EORTC QLQ-BN20, keluhan terbanyak nyeri kepala 49,2 $\pm 37,7$. Lokasi tumor merupakan faktor yang memengaruhi kualitas hidup.

Diskusi: Kualitas hidup subjek penelitian baik berdasarkan EORTC QLQ-C30 dan EORTC QLQ-BN20. Hasil sesuai dengan beberapa penelitian sebelumnya, namun penilaian dilakukan sebelum dan setelah tindakan. Evaluasi adanya perubahan kualitas hidup seharusnya dilakukan sebelum dan setelah tindakan. Penelitian ini hanya menilai subjek setelah tindakan di instalasi rawat jalan. Untuk kedepannya, perlu dilakukan penelitian kohort untuk penilaian kualitas hidup.

Kata kunci: EORTC QLQ-BN20, EORTC QLQ-C30, kualitas hidup, tumor primer intrakranial

*Bagian Neurologi FK Universitas Padjadjaran/RSUP Dr. Hasan Sadikin, Bandung. Korespondensi: dr.ratihpuspa@ yahoo.com. 


\section{PENDAHULUAN}

Tumor intrakranial memiliki prevalensi sebanyak 5,8\% per 100.000 tumor pada manusia. Angka kejadian tumor primer intrakranial di dunia sebesar 4,3-18,6\% per 100.000 penduduk per tahun. Berbagai gejala dan tanda klinis baik umum yang diakibatkan tumor primer intrakranial seperti nyeri kepala, kelelahan, depresi, anoreksia, mual, kejang, gangguan tidur, dan gangguan kepribadian; maupun defisit fokal seperti kelemahan motorik, afasia, dan gangguan lapang pandang dapat menjadi penyebab penurunan kualitas hidup. ${ }^{1-2}$

Kualitas hidup merupakan sebuah konsep parameter yang mencakup kesejahteraan multidimensional seseorang dan mencerminkan kepuasan individu secara keseluruhan. Parameter ini terdiri dari beberapa dimensi, seperti status fisik atau status fungsional, status emosi, dan status sosial. Kualitas hidup digambarkan sebagai rentang antara harapan pasien dengan keadaan yang sebenarnya, semakin kecil rentang tersebut maka kualitas hidup akan semakin meningkat. ${ }^{4}$

Pasien dengan tumor primer intrakranial perlu dilakukan penilaian kualitas hidup untuk mengevaluasi tata laksana yang akan atau telah diberikan. Perbedaan lokasi dan jenis tumor akan menentukan jenis terapi yang diberikan yang dapat memengaruhi kualitas hidup pasien. Kualitas hidup juga merupakan areayang penting untuk mengevaluasi prognosis pada bidang neuroonkologi. ${ }^{5-6}$

European Organization for Research and Treatment of Cancer (EORTC) membuat parameter multidimensional dari kualitas hidup pada semua pasien tumor dengan menggunakan 30 pertanyaan (Quality of Life Questionnaire/QLQ-C30) yang telah divalidasi ke dalam Bahasa Indonesia. Khusus untuk tumor intrakranial, digunakan EORTC QLQBrain Cancer Module (EORTC QLQ-BN20) yang mengandung 20 pertanyaan dan sudah diterjemahkan ke dalam Bahasa Indonesia, walaupun belum divalidasi. ${ }^{7-9} \quad$ Penggunaan gabungan keduanya diharapkan memiliki nilai keakuratan yang lebih tinggi dalam menilai kualitas hidup pasien tumor intrakranial.

Penilaian lain, yaitu Karnofsky Performance Scale (KPS) digunakan sebelum melakukan penilaian dengan EORTC QLQ-C30 dan QLQ-BN20, untuk menilai status fungsional pasien dengan keganasan sistemik. Adapun Eastern Cooperative Oncology Group (ECOG) Performance Scale digunakan juga untuk menilai status fungsional pasien tumor yang telah dilakukan penatalaksanaan terhadap tumornya. ${ }^{4,711}$

Penelitian tentang penilaian kualitas hidup dengan menggunakan EORTC QLQ-C30 dan EORTC QLQ-BN20 khususnya untuk tumor primer intrakranial masih sedikit, sehingga pedoman klinisi tentang hal ini terbatas. Untuk di Indonesia sendiri, penggunaan dua kuesioner tersebut secara bersamaan untuk penilaian kualitas hidup pada pasien tumor intrakranial belum pernah dilaporkan. Melalui penelitian ini, akan diteliti dan dinilai kualitas hidup pasien tumor primer intrakranial menggunakan EORTC QLQ-C30 bersamaan dengan EORTC QLQBN20.

\section{TUJUAN}

Menilai kualitas hidup pada pasien tumor primer intrakranial pascatindakan dengan menggunakan EORTC QLQ-C30 bersamaan dengan EORTC QLQ-BN20.

\section{METODE}

Penelitian ini deskriptif analitik dengan rancangan potong lintang terhadap pasien dengan tumor intrakranial yang berobat ke instalasi rawat jalan neurologi, bedah saraf, dan radioterapi RSUP Dr. Hasan Sadikin, Bandung secara konsekutif pada bulan Desember 2017 hingga Januari 2018. Kriteria inklusi adalah pasien dewasa yang terbukti menderita tumor primer intrakranial berdasarkan hasil histopatologi, sadar (Skala Koma Glasgow 15 ), kondisi umum baik dan kooperatif, KPS $\geq 50$, ECOG Performance Scale $\leq 2$, dan telah dilakukan penatalaksanaan terhadap tumor intrakranialnya (operatif, radiasi, dan atau kemoterapi). Kriteria eksklusi adalah pasien yang sedang dalam kondisi nyeri hebat yaitu NRS (Numeric Rating Scale) 8-10, memiliki gangguan komunikasi yang berat, dan tidak bersedia mengikuti penelitian.

Subjek dilakukan pengambilan data demografi dan karakteristik tumor, penilaian status fungsional berdasarkan KPS dan ECOG Performance Scale, serta penilaian kualitas hidup menggunakan EORTC 
QLQ-C30 dan EORTC QLQ-BN20. Status performa subjek dikatakan baik jika nilai KPS $\geq 50$ dan ECOG Performance Scale $\leq 2 .{ }^{10-12}$

EORTC QLQ-C30 dan EORTC QLQ-BN20 memiliki nilai 1-4 pada masing-masing pertanyaan dengan interpretasi disesuaikan kondisi pasien. Pada EORTC QLQ-C30, terdiri dari tiga skala utama yaitu: skala fungsional (5 ranah), skala kualitas hidup (1 ranah), dan skala keluhan (9 ranah); sedangkan EORTC QLQ-BN20, hanya terdiri dari skala keluhan (11 ranah).

Nilai yang didapat dari kedua kuesioner tersebut akan dihitung dua tahap, yaitu: ${ }^{12-15}$

1. Estimasi nilai rata-rata masing-masing pertanyaan dari masing-masing skala (merupakan nilai mentah).

Nilai mentah $/$ raw score $(\mathrm{RS})=(\mathrm{I} 1+\mathrm{I} 2+\ldots+\mathrm{In}) / \mathrm{n}$

2. Menggunakan transformasi linier (S) untuk menstandarisasi skor mentah, sehingga diperoleh hasil antara 0-100. Nilai yang tinggi menunjukkan tingginya tingkat fungsional (baik) atau tingginya tingkat keluhan (buruk).

Skala fungsional $: \mathrm{S}=\left\{1-\frac{(\mathrm{RS}-1)}{\text { Range }} \times 100\right\}$

Skala keluhan $: \mathrm{S}=\{(\mathrm{RS}-1) /$ range $\mathrm{x} 100\}$

Kualitas hidup $: \mathrm{S}=\{(\mathrm{RS}-1) /$ range $\mathrm{x} 100\}$

Range merupakan perbedaan antara kemungkinan nilai maksimum dari RS dan kemungkinan nilai minimum. EORTC QLQ-C30 memiliki range yang sama dari semua nilai yaitu 3 , kecuali nilai kualitas hidup yaitu 6. Adapun EORTC QLQBN20, transformasi linier menggunakan rumus yang digunakan pada skala keluhan, dan range adalah $3 .^{13-}$ 14

Dilakukan penghitungan rerata \pm SD pada masing-masing skala. Interpretasi nilai kualitas hidup mengikuti Lee dkk dan Kim dkk yang mendapatkan hasil bahwa nilai $\geq 50$ untuk masing-masing skala fungsional dan kualitas hidup pada EORTC QLQ-C30 menunjukkan kualitas hidup yang baik, sedangkan nilai $\geq 50$ untuk masing-masing skala keluhan pada EORTC QLQ-C30 dan EORTC QLQBN20 menunjukkan kualitas hidup yang buruk. ${ }^{12,16}$
Selanjutnya dilakukan penilaian hubungan antara masing-masing karakteristik demografi dan tumor primer intrakranial dengan nilai skala kualitas hidup yang didapat pada EORTC QLQ-C30, untuk mengetahui peran tiap karakteristik terhadap kualitas hidup. $^{16}$

Analisis data yang dilakukan secara umum bersifat deskriptif yang diolah dengan program SPSS versi 24.0 for Windows. Adanya hubungan antara karakteristik demografi dan tumor intrakranial dengan kualitas hidup dianalisis dengan menggunakan tabulasi silang menggunakan uji Chi-square.

\section{HASIL}

Terdapat 42 subjek (Tabel 1) dengan rerata usia 38,7 $\pm 11,9$ tahun yang kebanyakan perempuan $(73,8 \%)$ sebagai ibu rumah tangga $(54,8 \%)$, berpendidikan $\leq 9$ tahun $(61,9 \%)$, dan memiliki status performa yang baik, yaitu KPS 80-100 (69\%) dan ECOG $0(54,2 \%)$. Tumor tersering yang ditemui (Tabel 2) adalah glioma dan meningioma (masingmasing 47,6\%) dengan lokasi pada lebih dari 1 lobus $(71,4 \%)$, tanpa ada riwayat tumor pada keluarga sebelumnya $(92,9 \%)$.

Tabel 1. Karakteristik Subjek Penelitian $(n=42)$

\begin{tabular}{lc}
\hline \multicolumn{1}{c}{ Karakteristik } & $\mathbf{n}(\%)$ \\
\hline Usia $($ Rerata \pm SD: $38,7 \pm 11,9)$ & \\
- $\quad 18-25$ & $13(30,9)$ \\
- $\quad 26-45$ & $16(38,1)$ \\
- $\quad \geq 46$ & $13(30,9)$ \\
Jenis kelamin & \\
- $\quad$ Laki-laki & $11(26,2)$ \\
- $\quad$ Perempuan & $31(73,8)$ \\
Pekerjaan & \\
- Ibu rumah tangga/tidak bekerja & $23(54,8)$ \\
- $\quad$ Bekerja/pelajar & $19(45,2)$ \\
Pendidikan & \\
- $\quad \leq 9$ tahun & \\
- $>9$ tahun & $26(61,9)$ \\
KPS & $16(38,1)$ \\
- $\quad 80-100$ & \\
- $\quad 50-70$ & $29(69,0)$ \\
ECOG Performance Scale & $13(31,0)$ \\
- $\quad 2$ & \\
- $\quad 1$ & $5(11,9)$ \\
- $\quad 0$ & $15(35,7)$ \\
\hline KPS: Karnofsky Performance Scale; ECOG: Eastern Cooperative \\
Oncology Group.
\end{tabular}


Tabel 2. Karakteristik Tumor Primer Intrakranial dan Terapi $(n=42)$

\begin{tabular}{lc}
\hline \multicolumn{1}{c}{ Karakteristik } & n (\%) \\
\hline Jenis tumor & \\
- Glioma & $20(47,6)$ \\
- Meningioma & $20(47,6)$ \\
- Ependimoma & $2(4,8)$ \\
Lokasi berdasarkan jaringan & \\
- Intraaksial & $22(52,4)$ \\
- Ekstraaksial & $20(47,6)$ \\
Lokasi berdasarkan lobus & \\
- Lobus frontalis & $5(11,9)$ \\
- Lobus temporalis & $4(9,5)$ \\
- Lobus parietalis & $1(2,4)$ \\
- Lobus oksipitalis & $1(2,4)$ \\
- Batang otak & $1(2,4)$ \\
- Lainnya atau $>1$ lobus/lokasi & $30(71,4)$ \\
Riwayat tumor dalam keluarga & \\
- Ada & $3(2,4)$ \\
- Tidak ada & $39(92,9)$ \\
Jenis terapi & \\
- Operatif saja & $29(69,1)$ \\
- Operatif dan radiasi & $10(23,8)$ \\
- Operatif, radiasi, dan kemoterapi & $3(7,1)$ \\
\hline & temozolamid \\
\hline
\end{tabular}

Berdasarkan EORTC QLQ-C30 dan EORTC QLQ-BN20 yang didapat dari penelitian ini, rerata kualitas hidup pasien adalah baik (Tabel 3), yaitu skala fungsional $\geq 50$ dan skala keluhan $\leq 50$. Skala keluhan pada EORTC QLQ-C30 memiliki nilai paling rendah dari dua skala lainnya; sedangkan berdasarkan EORTC QLQ-BN20, hanya terdapat 4 dari 11 ranah yang memiliki nilai rerata $>50$ dengan keluhan terbanyak adalah nyeri kepala.

Tabel 4 menunjukkan lokasi tumor sebagai faktor yang dapat memengaruhi kualitas hidup secara bermakna $(\mathrm{p}=0,02)$.

\section{PEMBAHASAN}

Rerata usia subjek adalah $38,7 \pm 11,9$ tahun dan tumor tersering glioma. Hal ini sesuai dengan Bennett dkk, yaitu rerata usia 38 tahun dan tumor terbanyak jenis glioma (intraaksial) stadium awal. ${ }^{17}$ Berbeda dengan Lai dkk yang mendapatkan rerata usia subjek $52,2 \pm 11,1$ tahun dan glioma stadium lanjut (stadium III dan IV). ${ }^{18}$

Pada penelitian ini, mayoritas subjek penelitian adalah perempuan $(73,8 \%)$, sesuai dengan Lee dkk (60\%). ${ }^{12}$ Perempuan dikatakan lebih berisiko memiliki tumor intrakanial jenis meningioma akibat pengaruh hormonal. ${ }^{19}$

Karakteristik yang dapat memengaruhi kualitas hidup dalam penelitian ini yaitu lokasi tumor $(p=0,02)$. Subjek sebagian besar memiliki $>1$ lobus/ lokasi 59,5\%, dengan satu subjek memiliki kualitas hidup yang buruk, sedangkan subjek yang hanya memiliki lokasi pada 1 lobus tidak memengaruhi kualitas hidup. Sesuai dengan penelitian Florien W. Boele yang mendapatkan hasil 38,5\% yang memiliki kualitas hidup buruk. ${ }^{20}$ Penyebabnya karena lokasi pada $>1$ lobus memengaruhi beberapa fungsi dari otak yang terdapat tumor tersebut (sesuai dengan lokasi), sehingga terjadi penurunan fungsi dan kualitas hidup. ${ }^{20-21}$

Karakteristik lainnya tidak memengaruhi kualitas hidup dalam penelitian ini, yang memang dikarenakan subjek memiliki status performa yang baik sehingga hanya terdapat 2 subjek yang memiliki kualitas hidup buruk. Namun menurut beberapa penelitian di luar negeri, seperti Asko Niemela melaporkan bahwa jenis kelamin wanita memiliki kualitas hidup yang lebih buruk daripada pria dikarenakan pengaruh stres. ${ }^{22}$ Begitu juga penelitian yang dilakukan oleh Florien W. Boele, melaporkan bahwa subjek yang telah menikah memiliki kualitas hidup yang lebih buruk dikarenakan stres yang berpengaruh terhadap terjadinya onkogenesis dan replikasi tumor, pembentukan VEGF, dan faktor sitokin pro inflamasi yang selanjutnya akan membuat umpan balik terhadap terjadinya stres sehingga menurunkan kualitas hidup. ${ }^{20}$

Pada penelitian ini, kualitas hidup subjek penelitian berdasarkan EORTC QLQ-C30 mempunyai nilai yang paling tinggi pada skala fungsional terutama fungsi kognitif $81,4 \pm 30,2$. Hal ini sesuai dengan beberapa penelitian sebelumnya, yaitu Ooi Ai Lee pada fungsi emosi $80,5 \pm 25,5 .^{12}$ Begitu juga dengan penelitian yang dilakukan oleh Yong Soon Shin pada fungsi sosial 71,7 $\pm 30,7$, dan Chang-Wook Kim pada fungsi fisik $76,1 \pm 21,9 .^{16,23}$ Perbedaan skala fungsional yang tertinggi dari masing-masing penelitian kemungkinan disebabkan perbedaan 
Tabel 3. Kualitas Hidup berdasarkan EORTC QLQ-C30 dan EORTC QLQ-BN20

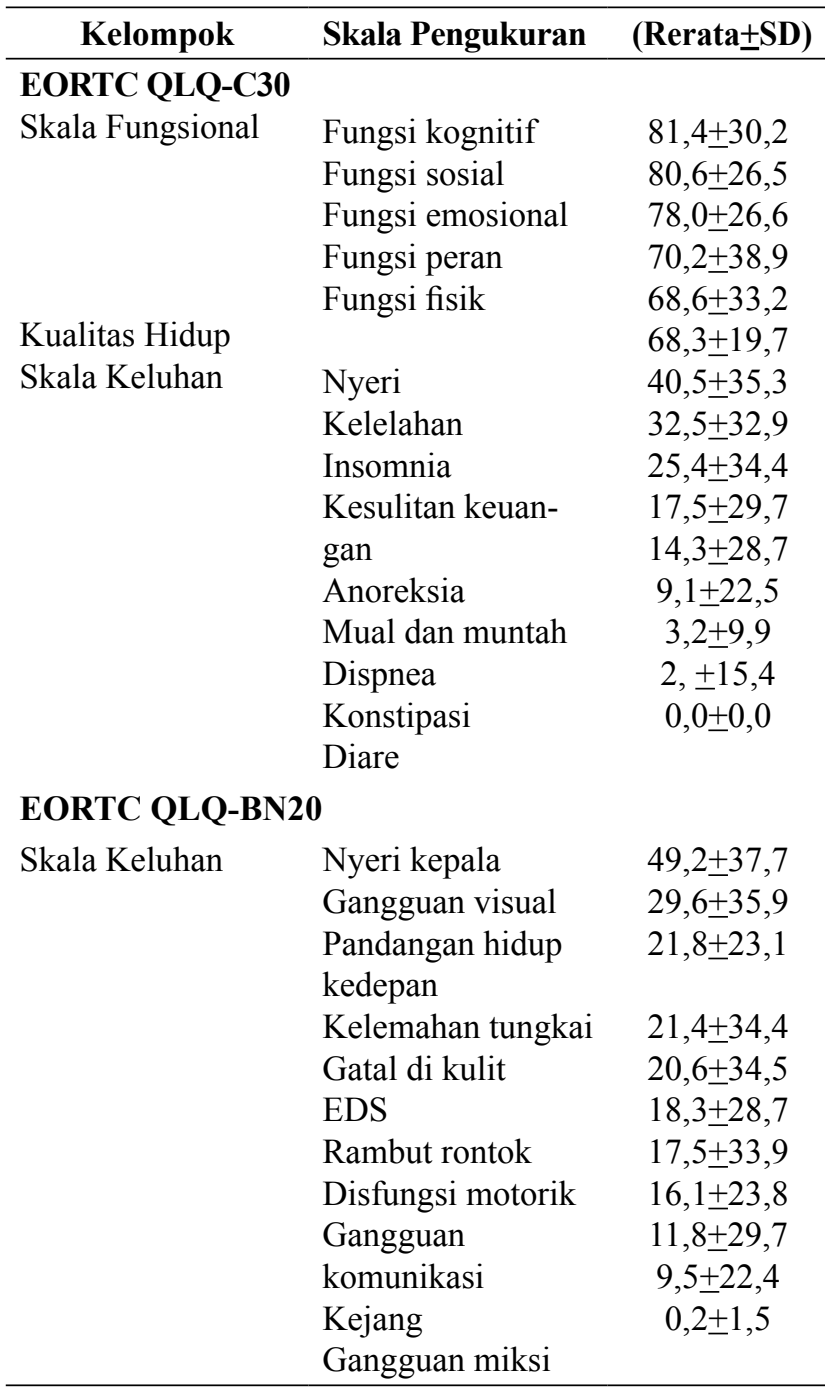

EORTC QLQ: European Organization for Research and Treatment of Cancer Quality of Life; $\mathrm{EDS}=$ Excessive daytime sleepiness.

ras, daerah/lokasi tempat tinggal, usia, dan tingkat pendidikan. ${ }^{12,16}$ Tingginya skala fungsional memiliki makna tingginya kualitas hidup. ${ }^{14}$

Pada skala kualitas hidup secara umum, hasil yang didapat pada penelitian ini $68,3 \pm 19,7$, yang juga sesuai dengan beberapa penelitian sebelumnya. Ooi Ai Lee mendapatkan hasil 56,5 $\pm 26,8$, Yong Soon Shin $54,2 \pm 25,2$, dan Chang-Wook Kim 62,5 $22,1.12,16,21$ Tingginya skala kualitas hidup secara umum menunjukkan tingginya kualitas hidup. ${ }^{14}$

Dari skala keluhan EORTC QLQ-C30, hasil yang didapat pada penelitian ini menunjukkan nilai dengan rerata $<80,0$. Skala keluhan merupakan skala
Tabel 4. Hubungan Karakteristik dengan Kualitas Hidup (n=42)

\begin{tabular}{|c|c|c|c|}
\hline Karakteristik & $\begin{array}{c}\text { QoL Baik } \\
\text { n (\%) }\end{array}$ & $\begin{array}{l}\text { QoL Buruk } \\
\text { n (\%) }\end{array}$ & $\mathbf{p}$ \\
\hline $\begin{array}{l}\text { Usia } \\
\text { - } \quad 18-25 \\
\text { - } \quad 26-45 \\
\cdot \quad \geq 46\end{array}$ & $\begin{array}{l}12(30) \\
16(40) \\
12(30)\end{array}$ & $\begin{array}{c}1(50) \\
0 \\
1(50)\end{array}$ & 0,56 \\
\hline $\begin{array}{l}\text { Jenis kelamin } \\
\text { - } \quad \text { Laki-laki } \\
\text { - } \quad \text { Perempuan }\end{array}$ & $\begin{array}{l}10(25) \\
30(75)\end{array}$ & $\begin{array}{l}1(50) \\
1(50)\end{array}$ & 0,46 \\
\hline $\begin{array}{l}\text { Pekerjaan } \\
\text { - Ibu rumah tangga/ } \\
\text { tidak bekerja } \\
\text { - Bekerja } \\
\text { - Pelajar/mahasiswa }\end{array}$ & $\begin{array}{c}23(54,8) \\
15(35,7) \\
4(9,5)\end{array}$ & $\begin{array}{c}0 \\
2(100) \\
0\end{array}$ & 0,25 \\
\hline $\begin{array}{l}\text { Pendidikan } \\
\text { - } \quad \leq 9 \text { tahun } \\
\text { - } \quad>9 \text { tahun }\end{array}$ & $\begin{array}{l}25(52,5) \\
15(37,5)\end{array}$ & $\begin{array}{l}1(50) \\
1(50)\end{array}$ & 0,78 \\
\hline $\begin{array}{l}\text { Jenis tumor } \\
\text { - } \quad \text { Glioma } \\
\text { - } \quad \text { Meningioma } \\
\text { - } \quad \text { Ependimoma }\end{array}$ & $\begin{array}{c}19(47,5) \\
19(47,5) \\
2(5,0)\end{array}$ & $\begin{array}{c}1(50) \\
1(50) \\
0\end{array}$ & 0,82 \\
\hline $\begin{array}{l}\text { Lokasi berdasarkan } \\
\text { jaringan } \\
\text { - Intraaksial } \\
\text { - Ekstraaksial }\end{array}$ & $\begin{array}{l}21(52,5) \\
19(47,5)\end{array}$ & $\begin{array}{l}1(50) \\
1(50)\end{array}$ & 0,89 \\
\hline $\begin{array}{l}\text { Lokasi berdasarkan } \\
\text { lobus } \\
\text { - }>1 \text { lobus/lokasi } \\
\text { - Lobus frontalis } \\
\text { - Lobus temporalis } \\
\text { - Lobus parietalis } \\
\text { - Lobus oksipitalis } \\
\text { - } \text { Batang otak } \\
\text { - Lainnya }\end{array}$ & $\begin{array}{c}24(58,5) \\
5(12,2) \\
4(9,8) \\
1(2,4) \\
1(2,4) \\
1(2,4) \\
5(12,2)\end{array}$ & $\begin{array}{c}1(100) \\
0 \\
0 \\
0 \\
0 \\
0 \\
0\end{array}$ & 0,02 \\
\hline $\begin{array}{l}\text { Riwayat keluarga } \\
\text { - Ada } \\
\text { - Tidak ada }\end{array}$ & $\begin{array}{c}3(7,5) \\
37(92,5)\end{array}$ & $\begin{array}{c}0(0,0) \\
2(100,0)\end{array}$ & 0,69 \\
\hline $\begin{array}{l}\text { Jenis terapi } \\
\text { - Operatif saja } \\
\text { - Operatif dan radiasi } \\
\text { - Operatif, radiasi, } \\
\text { dan } \\
\text { - Kemoterapi }\end{array}$ & $\begin{array}{c}27(67,5) \\
10(25,0) \\
3(7,5)\end{array}$ & $\begin{array}{c}2(100,0) \\
0(0,0) \\
0(0,0)\end{array}$ & 0,63 \\
\hline $\begin{array}{l}\text { Waktu pascatindakan } \\
\text { - } \quad \leq 3 \text { bulan } \\
\text { - } \quad>3 \text { bulan }\end{array}$ & $\begin{array}{l}24(60,0) \\
16(40,0)\end{array}$ & $\begin{array}{l}1(50,0) \\
1(50,0)\end{array}$ & 0,12 \\
\hline $\begin{array}{l}\text { KPS } \\
\text { - } \quad 80-100 \\
\text { - } \quad 50-70\end{array}$ & $\begin{array}{l}29(72,5) \\
11(27,5)\end{array}$ & $\begin{array}{c}0(0,0) \\
2(100,0)\end{array}$ & 0,16 \\
\hline $\begin{array}{l}\text { ECOG Performance } \\
\text { Scale }\end{array}$ & & & \\
\hline $\begin{array}{ll}- & 2 \\
- & 1 \\
- & 0\end{array}$ & $\begin{array}{l}4(10,0) \\
14(35,0) \\
22(55,0)\end{array}$ & $\begin{array}{l}1(50,0) \\
1(50,0) \\
0(0,0)\end{array}$ & 0,15 \\
\hline
\end{tabular}


terendah dibandingkan dua skala yang lain. Nilai tertinggi dari skala keluhan adalah nyeri 40,5 $\pm 35,3$. Beberapa penelitian sebelumnya juga menunjukkan hasil yang sama, yaitu skala keluhan lebih rendah dibandingkan dua skala yang lain, seperti Lee pada nyeri $(21,9 \pm 25,9)$; Shin pada kelelahan $(37,4 \pm 23,0)$; dan Kim pada kelelahan $(33,9 \pm 22,1) .{ }^{12,16,23}$ Perbedaan skala keluhan tertinggi dari masing-masing penelitian kemungkinan disebabkan perbedaan derajat keganasan tumor intrakranial dan kurun waktu pascatindakan. Rendahnya nilai skala keluhan yang didapat memiliki makna tingginya kualitas hidup. ${ }^{14}$

Adapun berdasarkan EORTC QLQ-BN20, hasil yang didapat dari penelitian ini menunjukkan nilai rerata $<90,0$ dengan terdapat empat dari sebelas ranah yang $\geq 50,0$, nilai tertinggi nyeri kepala $49,2 \pm 37,7$. Hasil sesuai dengan Lee pada gangguan visual $35,4 \pm 36,2$, Shin pada excessive daytime sleepiness (EDS) 43,3 $\pm 28,0$; dan Kim pada EDS $34,7 \pm 26,3$. Ketiga penelitian tersebut melakukan penilaian sebelum dan setelah terapi. ${ }^{12,16,23}$ Hasil pada penelitian ini menunjukkan bahwa rerata kualitas hidup baik, karena hanya terdapat empat dari sebelas ranah yang nilainya $\geq 50,0$. Hasil yang sama juga didapatkan pada beberapa penelitian sebelumnya, yaitu kualitas hidup baik. Nilai $<50,0$ memiliki interpretasi kualitas hidup baik..$^{12,14,16,23}$ Seperti skala keluhan QLQ-C30, pada QLQ-BN20 ranah yang ada merupakan skala keluhan, sehingga adanya perbedaan nilai yang tertinggi dari masing-masing penelitian kemungkinan disebabkan perbedaan staging tumor dan kurun waktu pascatindakan yang dilakukan.

Dari hasil yang didapat berdasarkan kedua kuesioner tersebut, didapatkan hasil bahwa pada penelitian ini kualitas hidup subjek penelitian baik, yang sesuai dengan beberapa penelitian sebelumnya di atas. Akan tetapi penelitian sebelumnya melakukan penilaian sebelum dan setelah tindakan. ${ }^{12,16,23}$

Nilai kualitas hidup yang baik menunjukkan bahwa tindakan yang telah dilakukan berhasil, sehingga gejala dan tanda klinis yang ada berkurang. Subjek pada penelitian ini merupakan pasien rawat jalan yang telah menjalani tindakan/tata laksana terhadap tumornya dan berdasarkan anamnesis mengalami perbaikan setelah menjalani tata laksana tersebut. ${ }^{12,14,16,23}$ Berbedanya nilai tertinggi yang didapat masing-masing skala dari masing-masing penelitian kemungkinan dikarenakan subjek berbeda populasi (jumlah, waktu pascatindakan, tindakan yang telah dilakukan, dan lain-lain).

Keterbatasan pada penelitian ini adalah penelitian dilakukan secara potong lintang dengan menggunakan hasil yang didapat pada saat kontrol ke instalasi rawat jalan pascatindakan (hanya dilakukan satu kali), tidak membandingkan hasil sebelum dan setelah tindakan. Penelitian ini menggunakan subjek penelitian yang tidak homogen dalam hal kurun waktu pascatindakan, yang seharusnya dilakukan 3-6 bulan pascatindakan seperti penelitian lain yang dilakukan di Korea dan Cina.

\section{KESIMPULAN DAN SARAN}

Kualitas hidup subjek penelitian baik, yang memang disebabkan karena subjek merupakan pasien rawat jalan yang telah menjalani tata laksana terhadap tumornya dan karena kriteria inklusi adalah subjek dengan status performa yang baik. Faktor yang dapat memengaruhi kualitas hidup adalah lokasi tumor.

\section{DAFTAR PUSTAKA}

1. Wen YP, Kesari S. Neurooncology. Dalam: Samuels MA, Ropper AH. Samuels manual of neurologic therapeutic. Philadelphia, Lippincott: Williams \& Walkins; 2010. h. 120-2.

2. Alentorn A, Hoang-Xuan K, Mikkelsen T. Presenting signs and symptoms in brain tumors. InHandbook of Clinical Neurology. Elsevier. 2016;134(3):19-26.

3. De-Robles P, Fiest KM, Frolkis AD, Pringsheim T, Atta C, dkk. The worldwide incidence and prevalence of primary tumors: a systematic review and metaanalysis. Neurooncol. 2015;17(6):776-83.

4. Liu R, Page M, Solheim K, Fox S, Chang SM. Quality of life in adults with brain tumors: current knowledge and future directions. Neurooncology. 2008:11(3):330-9.

5. Chang SM, Dunbar E, Dzul-Church V, Koehn L, Page MS. End of life care for brain tumor patients manual fo health care providers. Neuro-oncology gordon murray caregiver program. San Fransisco: University of California; 2014.

6. Friedman H, Liau L. Brain tumor guide for the newly diagnosed. New York: Musella Foundation For Brain 
Tumor: Research And Information; 2013.

7. Velikova G, Coens C, Efficace F, Greimel E, Groenvold M, Johnson C, dkk. Health-related quality of life in eortc clinical trials - 30 years of progress from methodological developments to making a real impact on oncology practice. EJC Suppl. 2012;10(1):141-9.

8. Perwitasari DA, Atthobari J, Dwiprahasto I, Hakimi M, Gelderblom H, Putter H, dkk. Translation and validation of EORTC QLQ-C30 into Indonesian version for cancer patients in Indonesia. Japanese $\mathrm{J}$ Clin Oncol. 2011;41(4)519-29.

9. Chen E, Nguyen J, Zhang L, Zeng L, Holden L, Lauzon N, dkk. Quality of life in patients with brain metastases using the EORTC QLQ-BN20 and QLQ-C30. J Radiation Oncol. 2012;1:179-86.

10. Chow R, Ray S, Tsao M, Pulenzas N, Zhang L, Sahgal A, dkk. Quality of life with brain symptom and impact questionnaire in patients with brain metastases. Ann Palliat Med. 2016;5(3):179-89.

11. Panciroli C, Estival A, Lucente G, Velarde JM, Garcia R, Vila L, dkk. ECOG or Karnofsky performance status to assess functionally in glioblastoma patients among different observers. J Mol Biomark Diagn. 2017;2017(S2):032.

12. Ooi AL, Mazlina M. Functional status and health-related quality of life in patients with primary intracranial tumours. Med $\mathrm{J}$ Malaysia. 2013;68(6):448-52.

13. Noviyani R, Tunas K, Indrayathi A, Budiana NG. Uji validitas dan reabilitas kuesioner EORTC QLQ-C30 untuk menilai kualitas hidup pada pasien kanker ginekologi di RSUP Sanglah Denpasar [Tesis]. Denpasar: Universitas Udayana; 2016.

14. QL Coordinator. EORTC QLQ-C30 scoring manual. Brussells: EORTC data center; 2001.

15. Taphorn MJ, Claassens L, Aaronson NK, Coens C, Mauer M, Osoba D, dkk. An international validation study of the EORTC brain cancer module (EORTC QLQ-BN20) for assessing health-related quality of life and symptoms in brain cancer patients. Eur $\mathbf{J}$ Cancer. 2010;46(6):1033-40.

16. Kim CW, Joo JD, Kim YH, Nan JH, Kim CY. Healthrelated quality of life in brain tumor patients treated with surgery: preliminary result of a single institution. Brain Tumor Res Treat 2016;4(2):87-93.

17. Bennett SR, Cruickshank G, Lindenmeyer A, Morris SR. Investigating the impact of headaches on the quality of life of patients with glioblastoma multiforme: a qualitative study. BMJ Open 2016;6:e011616.

18. Lai JS, Jensen SE, Beaumont JL, Abenethy AP, Jacobsen PB, Syjala K, dkk. Development of a symptom index for patiets with primary brain tumours. Value Health. 2014;17(1):62-9.

19. Ostrom QT, McCulloh C, Chen Y, Devine K, Wolinski Y. Family history of cancer in benign brain tumor subtypes versus glioma. Frontiers of Oncology. 2012;2:19.

20. Boele FW, Douw L, Reijneveld JC, Robben RB. Taphoorn MJ, Aaronson NK, dkk. Health-related quality of life in satble, long term survivors of low grade glioma. J Clin Oncol. 2015; 33(9):1023-9.

21. Cheng JX, Liu BL, Zhang X, Lin W, Zhang YQ, Liu WP, dkk. Health-related quality of life in glioma patients in China. BMC Cancer. 2010;10(1):305.

22. Niemela A, Koivukangas J, Herva R, Hakko H, Rasanen P, dkk. Gender difference in quality of life among brain tumor survivors. J Neurol Neurophysiol. 2011;2:4.

23. Shin YS, Kim JH. Validation of the Korean version of the european organization for research and treatment of cancer brain cancer module (EORTC QLQ-BN20) in patients with brain tumors. Health and Quality of Life Outcomes. 2013;11(1):145. 